\title{
Polychaeta Organism Density in Na Thap Estuary
}

\author{
Chokchai Lueangthuwapranit (Corresponding author) \\ Department of Fisheries Technology, Faculty of Science and Technology \\ Prince of Songkla University, Pattani 94000, Thailand
}

Tel: 66-73-313-930 Ext. $1870 \quad$ E-mail: gchokchai@gmail.com

Niwadee Saheem

Department of Mathematics and Computer Science, Faculty of Science and Technology

Prince of Songkla University, Pattani 94000, Thailand

Tel: 66-81-099-1005 E-mail: new_dee01@hotmail.com

Received: June 9, 2011 Accepted: June 22, 2011 doi:10.5539/ijb.v3n4p30

\begin{abstract}
Polychaeta is a class of macrobenthic fauna found in marine and estuarine environments. As part of a larger study of environment health impacts associated with the operation of a thermal power plant in the Na Thap River in Songkhla, Thailand, we examined bi-monthly organism densities of Polychaeta measured at each of five sites along the river downstream from the power plant for before and after its operation began. These densities, after log-transformation to reduce skewness with appropriate handling of zeroes, were found to be related to salinity measured at the same sites on the same occasions. There was also a statistically significant trend in the Polychaeta densities over the whole period.
\end{abstract}

Keywords: Polychaeta class, Macro-benthic fauna, Salinity, Na Thap River, Data transformation, Regression model

\section{Introduction}

Scientific studies commonly involve comparisons of means and rates with respect to study factors of interest. For example, an environmental study may investigate the variation of an outcome of interest such as the mean abundance of a species of fish at specific locations along a river. Physical and chemical study factors include water characteristics such as salinity and its related variables (chloride, hardness, total alkalinity and sulphate), water temperature and transparency, turbidity, total suspended solids, dissolved oxygen content, biochemical oxygen demand, heavy metal concentrations, and nitrate and phosphate concentrations. Biological determinants include species at lower levels in the food chain such as phytoplankton and zooplankton abundances.

Polychaeta is a class of macro-benthic fauna that inhabits estuaries of rivers, and its abundance is a biological index of the health of the estuarine environment. Polychaeta densities are related to temperature, transparency, salinity, oxygen demand, $\mathrm{pH}$ and minerals (Edgar, 1991). Polychaeta such as Capitella sp. and Theora lubrica in the family Capitellidae (Kikuchi, 1991; Ferraro et al., 1991) and Polydora sp. are biological indicators of organic pollutants. They are usually found in estuaries that contain hydrogen sulfide $\left(\mathrm{H}_{2} \mathrm{SO}_{4}\right)$ and high organic matter (Chareonpanich et al., 1994).

For such studies, regression analysis is an appropriate method for measuring differences in these means or rates of interest, and for assessing the statistical significance of their differences. Furthermore, this method can take into account distortions due to the effects of covariates that that can mask or amplify the magnitudes of these differences. Such methods are well established and comprehensively explained in the statistical literature (see, for example, Fox 1997, Venables and Ripley, 2002).

The thermal power plant is located in Chana district, Songkhla province covering 300 acres. It has production capacity of $700 \mathrm{MW}$ by fueling with natural gas from the Thai-Malaysian Joint Development Area in Gulf of Thailand and using approximately 39,000 cubic meters per day of water from Na Thap River for cooling the system. It started to operate the system in January 2008 until present. 
In this paper we used these methods to investigate the trend of Polychaeta abundance and its relation with salinity variation in the Na Thap River estuary during a 5-year period from June 2005 to May 2010, as part of an environmental health assessment program of a thermal power plant that began operation at the middle of this period.

\section{Materials and Methods}

\subsection{Data sampling}

The data used in this study were collected from the Na Thap River on a bi-monthly basis during a period from June 2005 to May 2010 at 5 sites (stations) in the river, located in brackish and saline water (Figure 1).

Water samples from each site were collected by using 1 liter plastic bottles in size for measuring salinity. Polychaetes were collected by using Ekman dredge $15 \times 15 \mathrm{~cm}^{2}$ to sieve with 420 micrometre mesh size. The samples were stored in 5\% formalin solution in the laboratory. Each species were counted and classified under a stereoscope (Fitter and Manuel, 1986).

\subsection{Statistical methods}

Linear regression (see, for example, Cook and Weisberg, 1999) is a statistical method widely used to model the association between a continuous outcome and a set of fixed determinants. The model expresses the outcome variable $\mathrm{y}$ as an additive function of the determinants. For example, if there are two determinants $\mathrm{x}_{1}$ and $\mathrm{x}_{2}$, the model takes the form.

$$
\mathrm{y}=\mathrm{a}+\mathrm{b}_{1} \mathrm{x}_{1}+\mathrm{b}_{2} \mathrm{x}_{2}
$$

The model also assumes that the errors are independent and normally distributed with mean 0 and constant standard deviation.

For biological outcomes such as organism counts per unit area or volume, the normality assumption is usually invalid due to skewness in the distribution of the outcomes. In this case the skewness may be reduced substantially by taking logarithms of the outcomes, provided zero outcomes are handled in some way. Clark and Warwick (1994) suggested replacing y by the transformed variable log (1+y). However, for ease of interpretation, results need to be expressed in terms of the organism densities themselves rather than transformed outcomes, so it is necessary to correct the back-transformed means to ensure that the overall mean organism density is preserved. Kongchouy and Sampantarak (2010) gave an appropriate method for modeling proportions using logistic regression, and their method also applies to means modeled using linear regression.

Equation (1) generalizes straightforwardly to any specified number of determinants, including categorical determinants that are treated as factors in the linear regression model. In such cases the parameters of interest are differences between parameters specifying the factor levels and their overall mean, and sum contrasts are needed to obtain appropriate confidence intervals for these differences.

We used the free and open-source basic R program (R Development Core Team, 2007) for all statistical and graphical analysis.

\section{Results and Discussion}

(Figure 1)

Figure 1 shows map of sampling stations along Na Thap River. The Na Thap River is has a watershed of approximately $232 \mathrm{~km}^{2}$. It originates at the confluence of Klong Pho Ma and Klong Luek, and after this 26.5 kilometers it flows into the Gulf of Thailand. Therefore, it is water body is a mixture of fresh and sea water subjecting it to receive many influences including tidal regimes, salinity influx, river flows, and surface runoff from the upland regions, resulting in unique characteristics of both the marine and freshwaters. The initial part of the river's body is narrow and rather deep with fresh water and thermal power plant is located in this part. The middle part is wider and shallower than the others and the estuarine part is narrow and deep and adjoins to the Gulf of Thailand.

(Figure 2)

Figure 2 shows histograms of Polychaeta organism densities, before (left panel) and after (right panel) transformation. This transformation reduces the skewness coefficient from 5.13 to 0.13 .

(Figure 3)

Figure 3 shows a plot of the transformed Polychaeta organism densities against months elapsed during the study period. Note that the fitted line is corrected by shifting its intercept to make it pass through the point for the 
mean organism density per square meter (14.4) at the mean number of months elapsed (30.7). The 95\% confidence interval for the slope is cantered at the end-point of the fitted line, and scaled to match the increase over the data range. The estimated trend obtained from this model is 1.52 percent per month $(95 \% \mathrm{CI} 0.42-$ 2.62).

(Figure 4)

The graph on the left of Figure 4 shows that adjusting for salinity reduces the trend very slightly. The adjusted trend estimate is 1.41 percent per month $(95 \%$ CI $0.34-2.46)$.

The graph on the right of Figure 4 shows a statistically significant relation between Polychaeta abundance and salinity after adjusting for the trend. The increase in the organism density was 2.81 percent ( $95 \%$ CI $1.01-4.61$ ) for each unit increase in salinity.

At all stations Polychaete density was statistically significantly related to month and water salinity. The salinity level increased with distance from the thermal power plant to the Gulf of Thailand. The amount of pumping for cooling the system is 39,000 cubic meters of water per day, which is very small compared to the water volume of the river. Thus we have little evidence that the power plant has an impact on the salinity level or temperature of the water.

In November, 2009 - April, 2010, Thailand faced a drought. The average monthly rainfall in the Eastern part of Southern Thailand from November 2009 until April 2010 was lower than the average monthly rainfall from 1950 to 1997. From December 2009 to April 2010 the average monthly rainfall in Chana district of Songkhla province was $15.7 \mathrm{~mm}$, while in the same months from 2005 to 2008, the average monthly rainfall was $76.9 \mathrm{~mm}$ (Sithicheewapaak, 2010). Thus, the drought led to intrusion of saltwater in Na Thap River, which can be observed from the increasing salinity along the river.

Sampling stations 2, 4 and 5 are surrounded by communities, shrimp farms, fish cage farms, pig farms, seafood processing factories, and rubber industry (Sapaeing, 2007). Waste water containing organic matter from those areas may cause increasing density of Polychaeta, whereas the location of the power plant is located upstream with less wastewater and organic matter.

\section{Conclusion}

Polychaeta organism densities in the Na Thap River estuary increased by an average of 1.5 percent per month over the five-year period from June 2005 to May 2010 inclusive, corresponding to a 90\% increase (95\% CI 25 157 percent) over the duration of the study. Given the volatility in the distribution of such organism counts, and the corresponding wide range given by the confidence interval, this result is not particularly conclusive. The impact of environmental factors on Polychaeta organism density in this area should be investigated for further study.

\section{Acknowledgements}

We are grateful to Professor Don McNeil for his helpful guidance.

\section{References}

Chareonpanich, C., Tsutsumi, H. \& Montani, S. (1994). Efficiency of the Decomposition of Organic Matter, Loaded on the Sediment, as a Result of the Biological Activity of Capitella sp. Marine Pollution Bulletin, 28: 314-318. http://dx.doi.org/10.1016/0025-326X(94)90157-0

Clarke, K.R. \& Warwick, R.M. (1994). Change in Marine Communities: An Approach to Statistical Analysis and Interpretation. United Kingdom: Plymouth Marine Laboratory.

Cook, R. D. \& Weisberg, S. (1999). Applied regression including computing and graphics. Hoboken, N.J.: John Wiley \& Sons. http://dx.doi.org/10.1002/9780470316948

Edgar, G. J. (1991). Distribution Patterns of Mobile Epifauna Associated with Rope Fibre Habitats with in the Bathurst Harbour Estuary, South-Western Tasmania. Estuarine, Coastal and Shelf Science, 33: 589-604. http://dx.doi.org/10.1016/0272-7714(91)90043-B

Ferraro, S. P., Swartz, R.C., Cole, F. A. \& Schults, D.W. (1991). Temporal Changes in the Benthos along a Pollution Gradient: Discriminating the Effects of Natural Phenomena from Sewage Industrial Waste Water Effects. Estuarine, Coastal and Shelf Science, 33: 383-407. http://dx.doi.org/10.1016/0272-7714(91)90064-I

Fitter, R. \& Manuel, R. (1986). Collins Field Guide to the Freshwater life of Britain and North-West Europe. Glaslow: Willium Collin Sons \& Co. ltd. 
Fox, J. (1997). Applied Regression Analysis, Linear Models and Related Methods. Thousand Oaks, CA: Sage.

Kikuchi, T. (1991). Macrobenthic succession in the organically polluted waters, and ecological characteristics of some pollution indicator species. In J. Mauchline, T. Nemoto, (eds). Marine biology, its accomplishment and future prospect (pp. 145-163). Tokyo: Hokusensha.

Kongchouy, N. \& Sampantarak, U. (2010). Confidence Intervals for Adjusted Proportions Using Logistic Regression. Modern Applied Science, 4: 2-7.

R Development Core Team. (2007). $R$ : A language and environment for statistical computing. R Foundation for Statistical Computing. Vienna, Austria: http://www.R-project.org.

Sapaeing, N. (2007). The Na Thap River life with the river. Songkhla: The Southern Coastal Resources Management Project of Thailand.

Sithicheewapaak, K. (2010). Climate in January-April 2010. Journal of Meteorology, 2: 8-10.

Venables, W.N. \& Ripley, B.D. (2002). Statistics and computing: Modern Applied Statistics with S., New York: Springer Science.

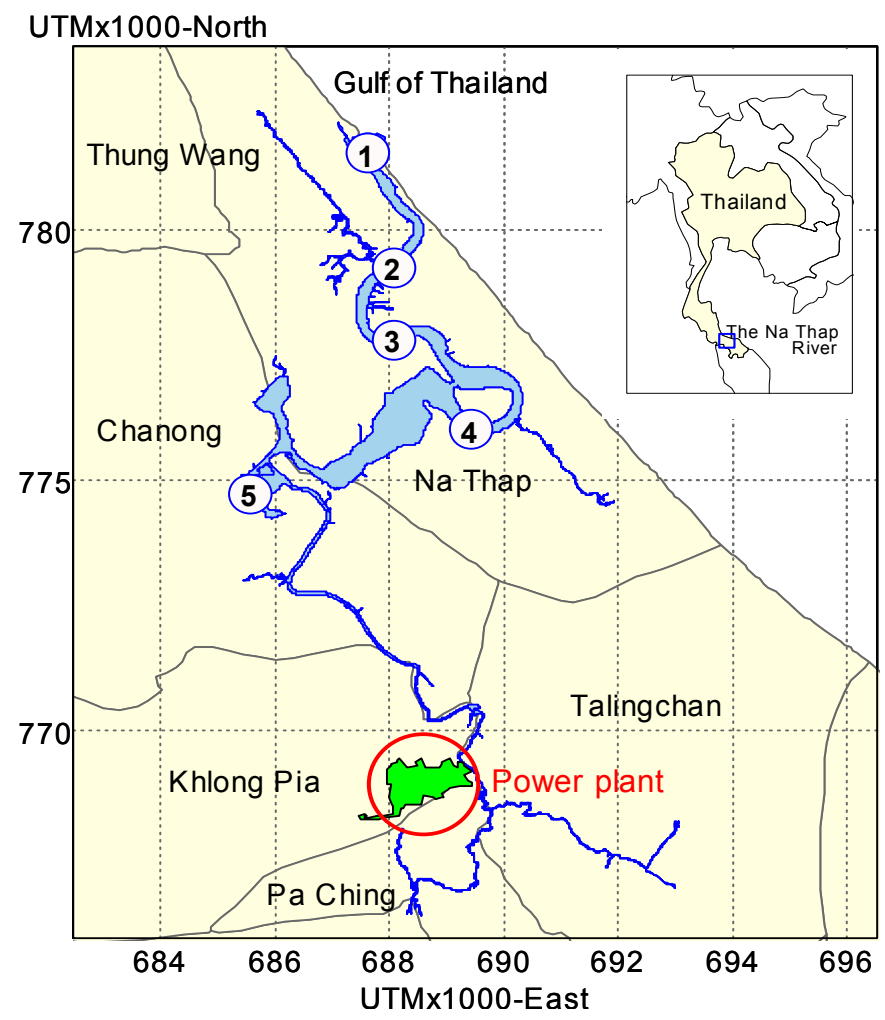

Figure 1. A map with sampling stations 

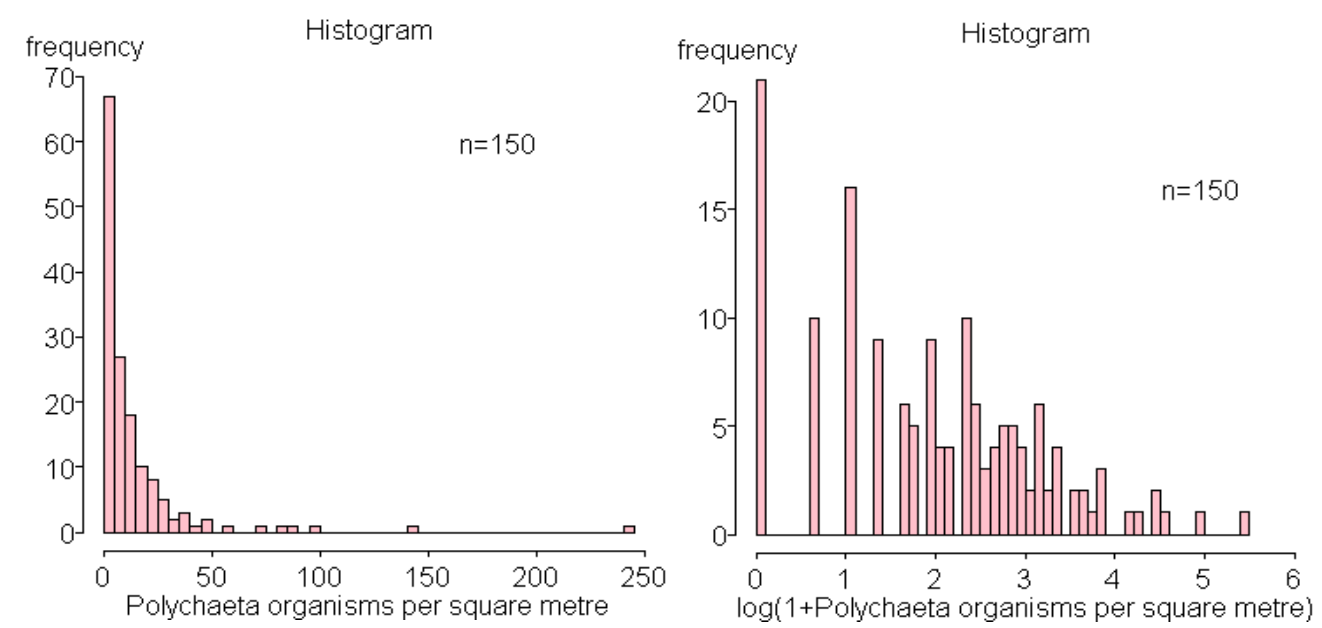

Figure 2. Histograms of Polychaeta organisms per square meter before (left panel) and after transformation using zero-corrected natural logarithms (right panel)

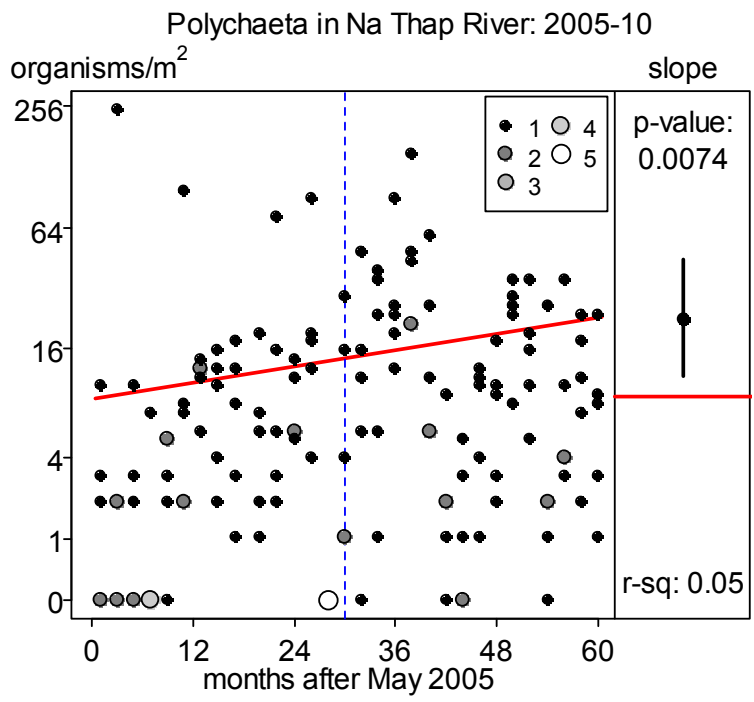

Figure 3. Polychaeta densities observed by months elapsed over duration of study with $95 \%$ confidence interval for gradient. The legend gives the number of overlapping points for observations from the 5 sites. The occasions when no Polychaeta were observed are as follows: at one site after 9, 32, 42 and 54 months, at two sites after 1, 3, 5 and 44 months, never at three sites, at four sites after 7 months, and at all five sites after 28 months. 
Polychaeta in Na Thap River: $2005-10$

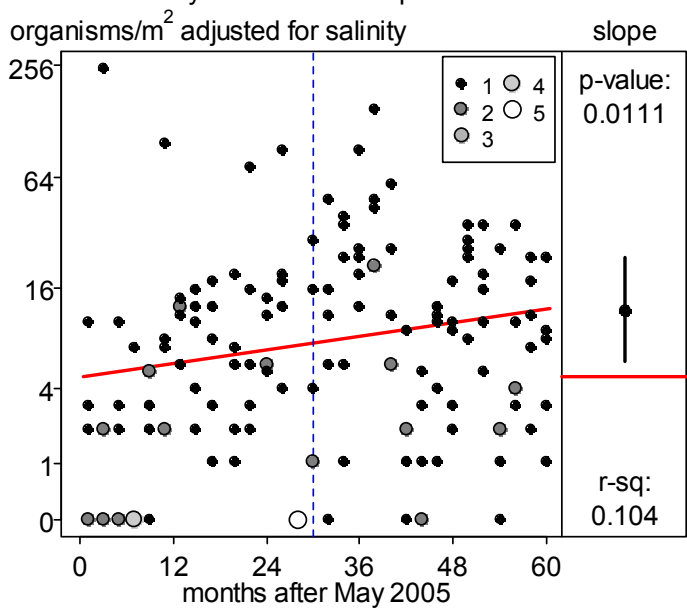

Polychaeta in Na Thap River: 2005-10

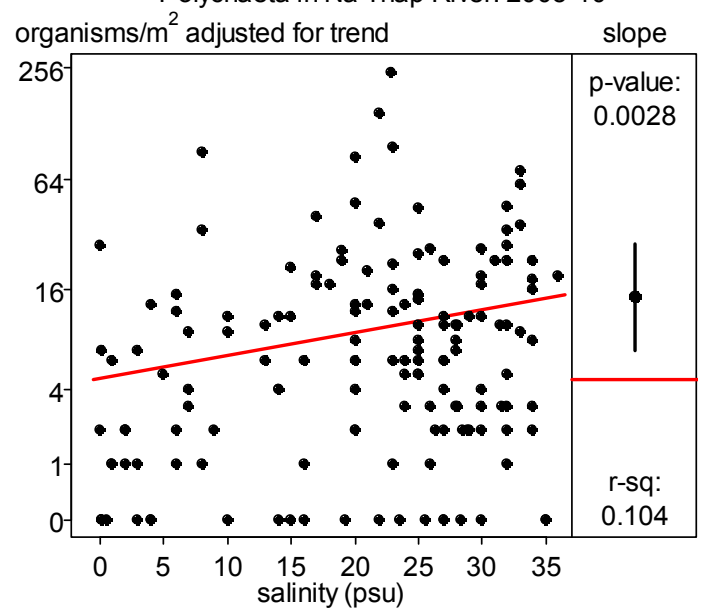

Figure 4. Polychaeta densities by month elapsed adjusted for salinity (left panel), and by salinity adjusted for trend (right panel) 